\title{
GOTO Telescope Motion Control System Right Ascension and Declination Direction with Three Modes of Speed Using Microcontroller ATMega2560
}

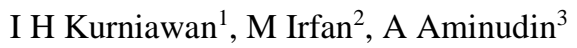 \\ \{ilhamhidayatk@gmail.com\} \\ Physics Education Department, Indonesia University of Education, Indonesia \\ Bosscha Observatory, Bandung Technology Institute, Indonesia ${ }^{1,2,3}$
}

\begin{abstract}
This research was pursued in a telescope motion control system that leads to right ascension and declination. This research will discuss and create a new system for telescopes that use the ATMega2560 microcontroller which is embedded in the Arduino Mega board as the brain of this system. The way this system works is first the ATmega2560 microcontroller will read the first position of the telescope after that the telescope will be moved by the hand box towards right ascension or declination and then the last position of the telescope will be read by the microcontroller. By using this latest system, the servo motor in the GOTO telescope can move with three-speed modes namely guide, set and slew where the speed of the guide requires a frequency of $1604 \mathrm{~Hz}$, the speed of the set requires a frequency of $51.340 \mathrm{~Hz}$ and the slew speed requires a frequency of 501,368 KHz.
\end{abstract}

Keywords: Telescope Motion, Arduino Mega Board

\section{Introduction}

This GOTO telescope consists of two electronic parts and non-electronic parts. The electronics section is the part that deals with all power supplies, data, motors and all matters related to GOTO electricity. While non-electronic parts, such as telescope materials, mirrors, mechanical parts such as gears and others. The entire body of the GOTO telescope is made of iron that is sturdy enough to protect the components inside including the electronic components. But over time, it is possible that the GOTO telescope will experience a decline in function. And that also happens now, the GOTO telescope is not functioning optimally as before. This has become one of the problems in the use of the GOTO telescope at this time.

This problem was discovered when an experiment after GOTO was repaired, one of the function buttons on the handbox did not work so when the observer pressed the GOTO telescope guide button it did not move at all. This problem causes the control system of the telescope is not optimal. To anticipate this problem, several solutions are needed. Among them is the creation of a new control system to optimize the performance of the GOTO telescope again.

The system is a combination of several components that work together and do a certain goal [1]. The system includes everything, can be about the cable network used, how to communicate between components, and how to make the output/output as desired. The GOTO telescope encountered a problem in the motion control system is applied. Therefore, research on the 
motion control system of the GOTO telescope in the direction of the ascensorecta and declination with three-speed modes using the ATMega2560 microcontroller is intended to make the latest system for the GOTO telescope so that the telescope can be reused.

\section{Methods}

The method used for this research is to test all components that will be used in the GOTO telescope. Testing this system is a step to strengthen that all components in the GOTO telescope are suitable for use in this telescope. This step starts from testing the board in the telescope joint right ascension section or RA board and then the declination section or DEC board, then testing with other components in the GOTO telescope such as the connecting board made by PT AERING, several sensors, hand box, servo drives and servo motors made from OMRON. And the last is testing all of the components of the GOTO telescope in order to find out the communication between the components in the GOTO telescope. The testing components can be seen on Figure 1 and the whole diagram on Figure 2.

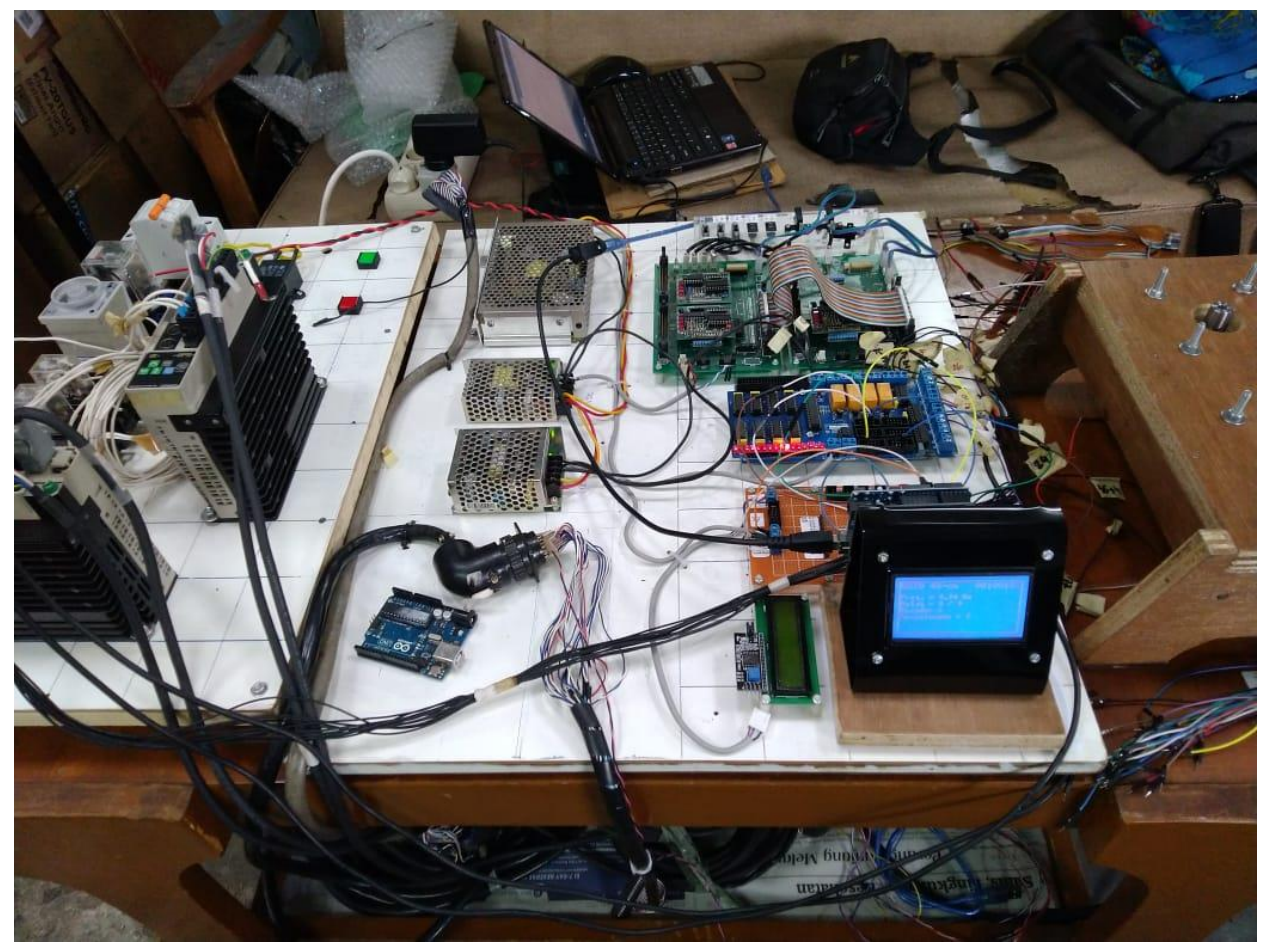

Fig. 1. Testing all of the components of telescope GOTO using Arduino Mega. 


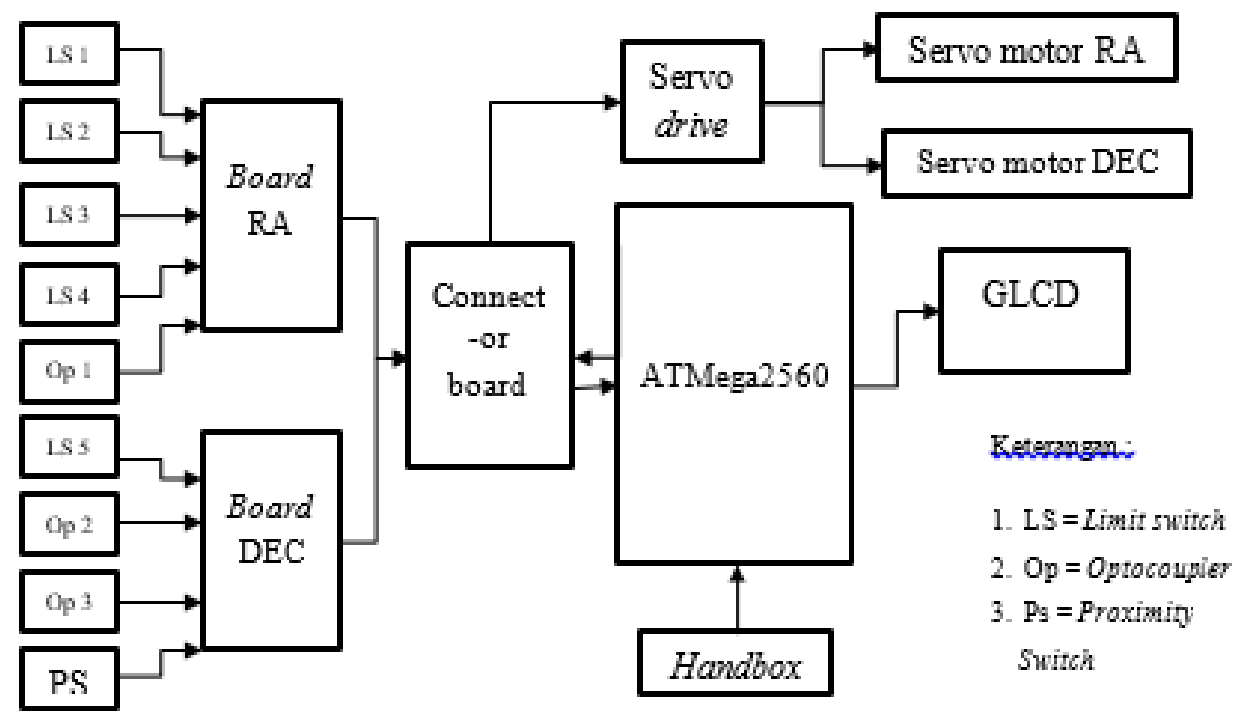

Fig. 2. The whole diagram for testing all of the components of GOTO Telescope.

The process is clear that the first user will choose one of three-speed modes namely slew, set, guide. Where each mode has its own speed. After that, the user will choose which direction the telescope will be moved north, south, west or east. All of this will be sent via a signal through a component called RS485 to the Arduino microcontroller.

After the microcontroller can read the signal given by the hand box. Arduino will execute the command by moving the servo motor in the right ascension joints and declination of the telescope. Servo motor is a motor that can work both ways, servo motor works with a closed feedback system where the position of the servo motor will be informed back to the control circuit that is inside the servo motor. Servo motor is a device or component that consists of a DC motor, a series of gears, a control circuit and a potentiometer [2]. A servo motor that moves is only one of the options, first right ascension or declination depending on the direction chosen by the right ascension for west and east, declination for north and south. The speed also depends on which model is chosen, Arduino will adjust according to the user's choice when pressing the hand box. The speed also depends on which mode is chosen. The signal Arduino commands to the servo motor is the frequency of PWM (Pulse with Modulation). Pulse Width Modulation PWM (pulse width modulation) is a digital signal conversion technique in the form of a square wave (square wave) where the duty cycle of the square wave can be set according to system requirements [3]. The bigger frequency is given by Arduino, the speed of the servo motor will be faster

When the telescope has moved as desired by the user. After that Arduino will read where the telescope's last position is. The position of the telescope can be determined by the switch that is in the body of the telescope. The switches in the telescope are micro switch, optocoupler and proximity switch. The position of the telescope will be determined by the condition of the switch contacted or not. This condition will send a signal to Arduino by the connecting board where there is a communication IC inside to tell which switches are in contact and not so that Arduino can deduce where the telescope is. 


\section{Results and Discussion}

Based on the manual book of this servo motor, this servo motor has an encoder resolution of $10,000 \mathrm{ppr}$ (pulse per rotation) meaning that in one rotation this motor requires 10,000 pulses [4]. This GOTO telescope has 1: 6912 reduction gear that meaning in one large rotation of the gear in the GOTO telescope requires 6912 rotation of the motor used [5]. With these two things, it can be concluded how many pulses are needed to produce one rotation, which 69.120 .000 pulse waves. In the GOTO telescope manual book, the speed of each speed is different, $2 x$ sidereal time for guide mode, $64 \mathrm{x}$ sidereal time for set mode and $625 \mathrm{x}$ sidereal time. When converted 1 sidereal day $=86164.1$ seconds synodic with this if 69.120 .000 pulses divided by 86164.1 seconds synodically will produce 0.0012456871 seconds / ppr. With this frequency will be found by the formula $\frac{1}{T}$. If $\frac{1}{0.0012456871}$ it will produce a frequency of $802 \mathrm{~Hz}$ if rounded. This frequency is the frequency needed to produce tracking speed. In accordance with the manual book of the GOTO telescope, guide mode has a speed of $2 \mathrm{x}$ tracking speed, this mode will require $1604 \mathrm{~Hz}$ frequency, set mode has a speed of $64 \mathrm{x}$ tracking speed, this mode will require a frequency of $51,340 \mathrm{~Hz}$ and slew mode has a speed of $625 \mathrm{x}$ speed tracking then requires a frequency of 501,368 Hz. Microcontroller sketch program can be seen on Figure 3 .

\begin{tabular}{|c|c|}
\hline 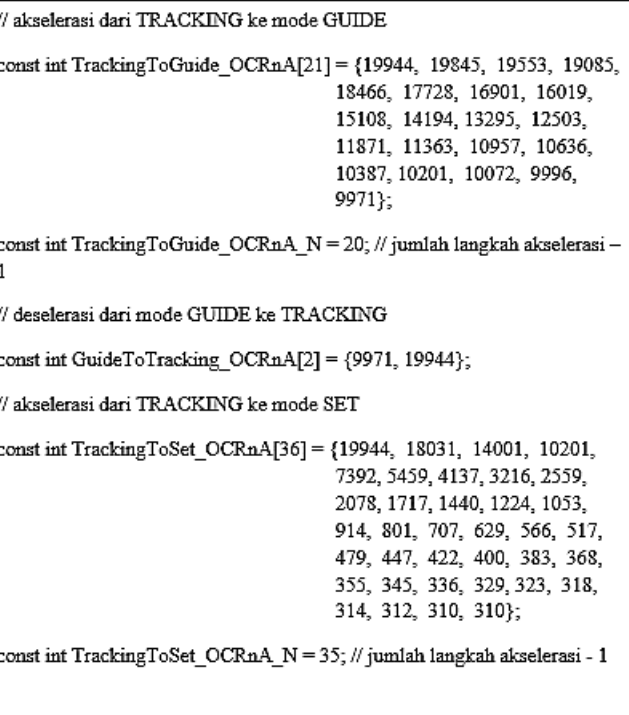 & 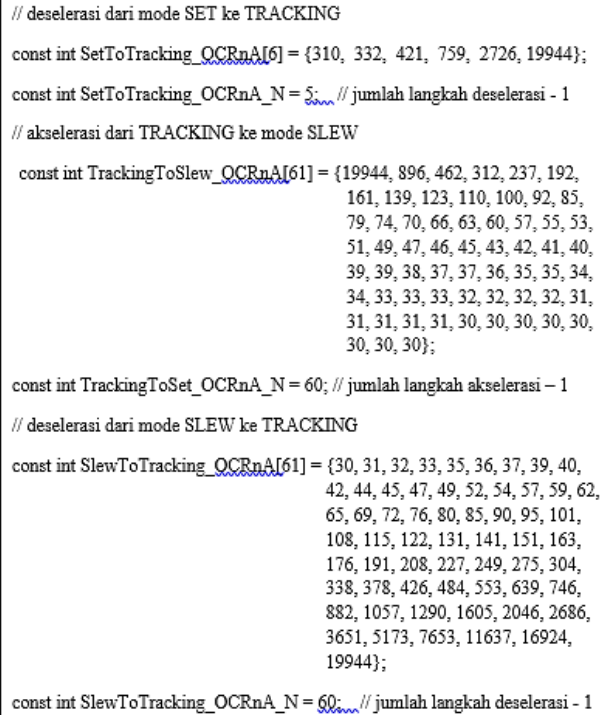 \\
\hline
\end{tabular}

Fig. 3. Microcontroller sketch program needed to drive the motor.

In the program, there is acceleration and deceleration soften the motor movement when it will move or stop because when going to change the speed mode the motor will move in the tracking speed first and then change the speed mode. The results of the program that have been made can be seen on Table 1 . 
Table 1. Result for testing servo motor RA and DEC.

\begin{tabular}{cccc}
\hline \multirow{2}{*}{ NO. } & Frequency $(\mathrm{Hz})$ & \multicolumn{2}{c}{ Motor condition } \\
\cline { 3 - 4 } & & RA & DEC \\
\hline $\mathbf{1}$ & 1.604 & Moved & Moved \\
\hline $\mathbf{2}$ & 51.340 & Moved & Moved \\
\hline $\mathbf{3}$ & 501.368 & Moved & Moved \\
\hline
\end{tabular}

Table 1 shows the results of the program created. The results of the table show that based on the frequency given and the accelerated deceleration made, the motor is still able to move optimally meaning that this new system can make the GOTO telescope move again in accordance with the GOTO manual book.

But sometimes the speed mode switches itself. This is because the components of the hand box that are not functioning optimally. As a result, the signal sent to the microcontroller is not stable so that sometimes the speed mode switches itself. This is alleged because the capacitors in the hand box are worn out which results in unstable currents in the hand box so that the signal being sent is unstable.

\section{Conclusion}

Based on the data and data analysis in the previous chapter, it can be concluded that:

1. The GOTO telescope can be moved towards right ascension and declination with three-speed modes in accordance with the manual book of the GOTO telescope where guide mode requires a frequency of $1,604 \mathrm{~Hz}$, set mode requires a frequency of $51,340 \mathrm{~Hz}$ and slew mode requires a frequency of $501,368 \mathrm{~Hz}$ to move

2. The program made for the ATMega2560 can make servo motors move the GOTO telescope towards the ascensorecta and declination with three-speed modes namely guide, set and slew

\section{References}

[1] Ogata, Katsuhiko. (1993). Teknik Kontrol Automatik (Sistem Pengaturan) Jilid 1. Jakarta : Erlangga.

[2] Rinaldy, Risa F. C. dan Didi, S. (2013). "Pengendalian Motor Servo yang Terintegrasi dengan Webcam Berbasis Internet dan Arduino". Purwokerto : Jurnal Infotel Vol.5 No.2 November 2013

[3] Birdayansyah, R., Noer, S., dan Osea, Z. (2015). "Pengendalian Kecepatan Motor DC Menggunakan Perintah Suara Berbasis Mikrokontroler Arduino". Lampung : Jurnal Rekayasa dan Teknologi Elektro Volume 9, No. 2, Mei 2015

[4] OMRON. (2012). "OMNUC G-series AC Servomotors/Servo Drives", www.ia.omron.com/products//. Acccesed on May 7th 2019

[5] Manual Book of GOTO Telescope 